\title{
Transient chylomicronemia preceding the onset of insulin-dependent diabetes in a young girl with no humoral markers of islet autoimmunity
}

\author{
Carlo M Barbagallo, Maurizio R Averna, Roberto Citarrella ${ }^{1}$, Manfredi Rizzo, Marco Amato ${ }^{1}$, Davide Noto, \\ Alberto Pugliese ${ }^{2}$, Angelo B Cefalù, Aldo Galluzzo ${ }^{1}$ and Carla Giordano ${ }^{1}$ \\ Department of Internal Medicine, ${ }^{1}$ Department of Endocrinology, Faculty of Medicine, Università di Palermo, Italy and ${ }^{2}$ Immunogenetics Program, \\ Diabetes Research Institute, University of Miami, Miami, FL, USA \\ (Correspondence should be addressed to C Giordano; Email: cgiordan@unipa.it)
}

\begin{abstract}
Objective: We investigated the possible causes of diabetes in a young child who presented with hyperglycemia associated with severe hypertriglyceridemia $(>166 \mathrm{mmol} / \mathrm{l})$, hypercholesterolemia $(>38 \mathrm{mmol} / \mathrm{l})$ and fasting chilomicrons.

Results: The patient did not have any of the HLA and autoantibody markers typically associated with type 1 diabetes. A glucose clamp failed to demonstrate insulin resistance (peripheral glucose utilization rate $(M)=4.3 \mathrm{mg} / \mathrm{kg}$ per $\mathrm{min}$ ) and there was no family history of type 2 diabetes or maturity onset diabetes in youth. Both fasting and stimulated C-peptide levels, including those in response to i.v. glucagon, were below the limit of detection. This is consistent with loss of $\beta$-cell function. The family history did not reveal the existence of relatives with lipid abnormalities, coronary heart disease, and pancreatitis. We did not find any abnormality of plasma apo $\mathrm{C}_{\mathrm{II}}$, lipoproteinlipase and hepatic lipase activities. The patients had a $\epsilon 3 / € 3$ apoE genotype and she rapidly cleared an oral fat load after normalization of plasma lipids.

Conclusions: The mild hyperglycemia seems an unlikely explanation for both the severe hypertriglyceridemia and chylomicronemia. A more plausible explanation is transient lipoproteinlipase deficiency. This rare condition, occasionally associated with a high-fat diet, could have caused the rapid and dramatic hypertriglyceridemia observed in this patient, which in turn might have led to the $\beta$-cell destruction by direct lipid toxicity.
\end{abstract}

European Journal of Endocrinology 150 831-836

\section{Introduction}

Type 1 diabetes mellitus occurs in genetically predisposed persons as a consequence of the immunemediated destruction of pancreatic islet $\beta$-cells that secrete insulin. The onset of clinically overt diabetes represents the end point of an insidious, progressive decline in the function of $\beta$-cells after the majority of $\beta$-cells have been damaged or destroyed (1). This asymptomatic preclinical phase, which may last from a few months to several years, is characterized by the appearance of autoantibodies against islet cell molecules such as insulin, glutamic acid decarboxylase (GAD), and a tyrosine-phosphatase-like protein known as anti-islet antigen 2 (IA-2). The presence of these antibodies is highly predictive of impending diabetes development and is considered a diagnostic marker of type 1 diabetes (2). Environmental factors may contribute to the possible development of the disease, but there is no evidence of a role for hyperlipidemia (3).
The chylomicronemic syndrome is a rare disorder characterized by massive hypertriglyceridemia and fasting chylomicronemia (4). At least two different genetic forms, lipoproteinlipase (LPL) or apoC $\mathrm{C}_{\mathrm{II}}$ deficiency, may be responsible for the disease. The former is relatively more frequent whereas the latter seems to have some peculiar clusters in Sicily $(5,6)$. A possible cause of the chylomicronemic syndrome may also be diabetes. Lack of LPL activity due to the insulin deficiency and consequent hyperglycemia has been postulated to cause fasting chylomicronemia (7). Finally, a condition of transient LPL deficiency has been described, but the prevalence of this form has not been investigated (8).

We report the onset of diabetes in a young child in whom the chylomicronemic syndrome was the main feature of her clinical presentation. Since we were able to exclude all of the most common causes of both disorders, we hypothesize that the rapid and massive hypertriglyceridemia, due to a possible transient LPL deficiency, may have led to $\beta$-cell destruction by a mechanism of 
direct lipid toxicity and finally to the development of an unusual form of insulin-dependent diabetes.

\section{Case report}

A 9-year-old girl developed symptoms of mild diabetes (polyuria, polydipsia, weight loss). She was hospitalized 2 weeks later. At that time she had fasting glucose levels $>11 \mathrm{mmol} / \mathrm{l}$ and urinary ketones. Plasma

Table 1 Lipoprotein parameters in the proband and relatives.

\begin{tabular}{|c|c|c|c|c|c|c|c|}
\hline & $\underset{(\mathrm{mmol} / \mathrm{l})}{\mathrm{CHO}}$ & $\begin{array}{c}\text { TG } \\
(\mathrm{mmol} / \mathrm{l})\end{array}$ & $\underset{(\mathrm{mmol} / \mathrm{l})}{\mathrm{HDL} \mathrm{C}}$ & apoE & apoC $_{\|}$ & Pvull & HindIII \\
\hline Probanc & 38.5 & 166.2 & NM & ع3/£3 & Present & $-1-$ & $-1-$ \\
\hline Father & 4.6 & 1.1 & 1.0 & ع3/є3 & NM & $+1-$ & $-1-$ \\
\hline Mother & 4.2 & 0.4 & 1.2 & ع3/ء3 & NM & $+1-$ & $-1-$ \\
\hline Brother & 4.5 & 0.5 & 1.1 & $\varepsilon 3 / \varepsilon 3$ & NM & $-1-$ & $-1-$ \\
\hline
\end{tabular}

$\mathrm{CHO}$, total cholesterol; TG, triglycerides; HDL C, HDL cholesterol; NM, not measured. triglyceride and cholesterol levels were dramatically elevated (triglyceride $>166 \mathrm{mmol} / \mathrm{l}$ and cholesterol $>38 \mathrm{mmol} / \mathrm{l})$ ) and fasting chylomicronemia was present (Table 1). Her parents reported that she had been fed a high-fat diet to compensate for her progressive weight loss, but this diet did not result in weight gain (see Fig. 1). Secondary causes of hyperlipidemia were excluded (e.g. hypothyroidism or kidney disease). A fundus oculi exam revealed a lipemia retinalis, and eruptive xanthomatosis was noted on the arm and head skin (Fig. 1). The patient also had elevated amylase levels and a CT scan showed signs of a mild pancreatitis. Infusion with saline and glucose solutions was instituted together with i.v. insulin therapy. This approach positively affected both glucose and lipid levels (Tables 2 and 3). Pancreatic enzymes fell into normal range within 3 days (data not shown). After 4 weeks, lipid levels were normalized and have remained so for up to 24 months. The lipemia retinalis as well as the eruptive xanthomatosis lesions also resolved. The exocrine pancreatic function was normal during
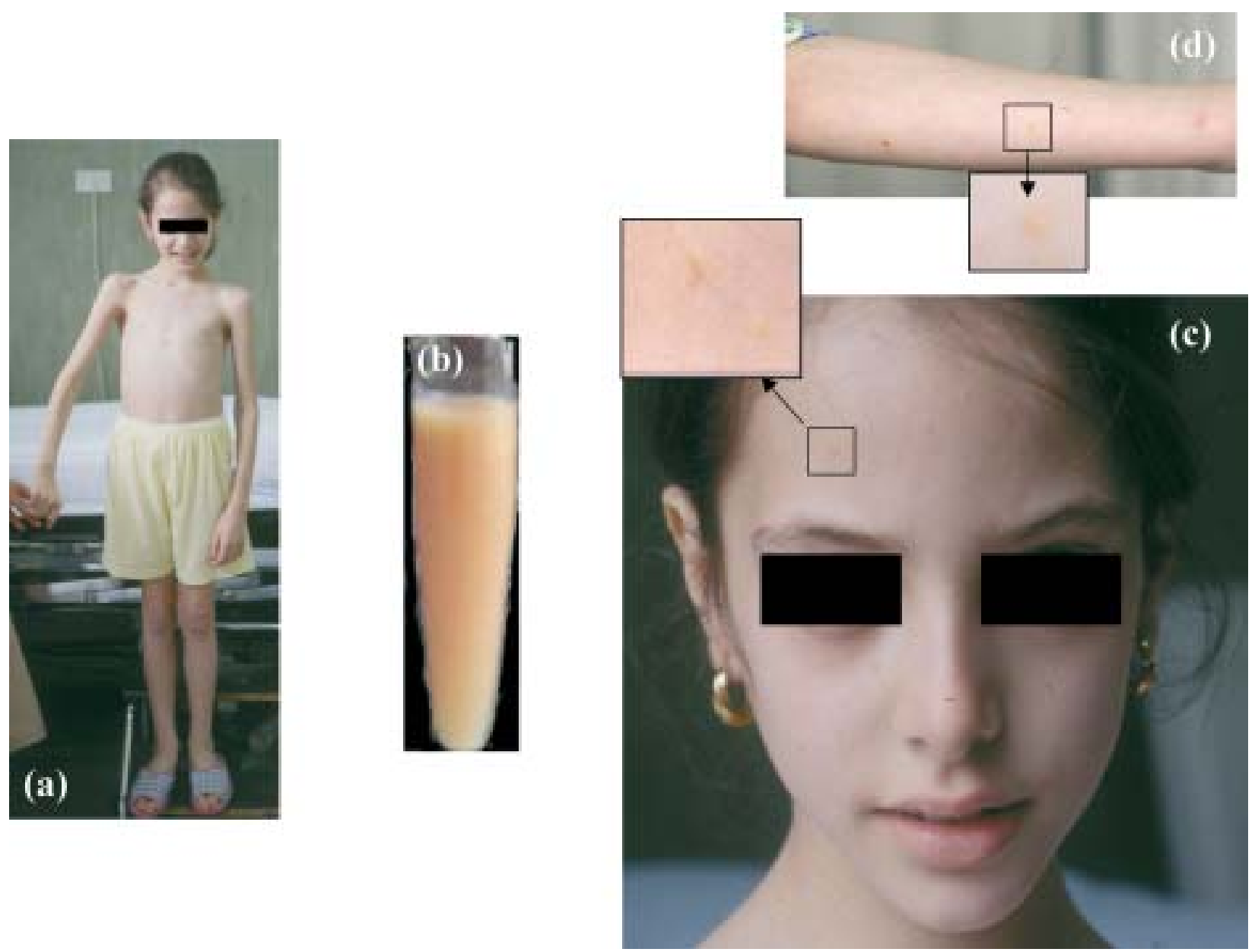

Figure 1 The proband at admittance (a), fasting chylomicronemia (b), and eruptive xanthomatosis on the head (c) and arm skin (d) with magnifications of two representative lesions. 
Table 2 Plasma lipids in a 9-year-old girl with severe triglyceride elevation and fasting chylomicronemia at admittance to hospital (day 1) and during the first 5 months.

\begin{tabular}{lcccc}
\hline Time & $\begin{array}{c}\text { CHO } \\
(\mathrm{mmol} / \mathrm{l})\end{array}$ & $\begin{array}{c}\text { TG } \\
(\mathrm{mmol} / \mathrm{l})\end{array}$ & $\begin{array}{c}\text { HDL C } \\
(\mathrm{mmol} / \mathrm{l})\end{array}$ & Chylo \\
\hline Day 1 & 38.5 & 166.2 & $\mathrm{NM}$ & + \\
Day 2 & 33.8 & 102.1 & $\mathrm{NM}$ & + \\
Day 3 & 21.7 & 63.2 & $\mathrm{NM}$ & + \\
Day 5 & 21.9 & 21.5 & $\mathrm{NM}$ & + \\
Day 6 & 21.4 & 16.1 & $\mathrm{NM}$ & + \\
Day 8 & 12.9 & 6.7 & $\mathrm{NM}$ & - \\
Day 9: enteral feeding & & & & \\
Week 2 & 10.3 & 6.9 & 0.4 & - \\
Week 3 & 9.0 & 3.0 & 0.7 & - \\
Week 4 & 4.8 & 0.6 & 1.3 & - \\
Month 3 & 3.1 & 0.4 & 1.4 & - \\
Month 5 & 3.4 & 0.3 & 1.7 & - \\
Month 6 & 3.2 & 0.3 & 1.8 & - \\
\end{tabular}

$\mathrm{CHO}$, total cholesterol; TG, triglycerides; HDL C, HDL cholesterol; Chylo, presence of fasting chylomicrons; NM, not measured.

the entire period of observation. The patient has diabetes and requires insulin injections, both short and long acting, four times a day.

\section{Materials and methods}

Blood samples were collected in the morning into EDTAcontaining tubes after a $12-14 \mathrm{~h}$ overnight fast. Total cholesterol, triglyceride, high-density lipoprotein (HDL) cholesterol, glycemia and urinary ketones were quantified by standard laboratory procedures. C-peptide levels were measured after i.v. glucagon (1 mg, bolus) using an ELISA method (Arnika, Milan, Italy). Glycated hemoglobin $\left(\mathrm{HbA}_{1 \mathrm{c}}\right)$ was measured by HPLC with a HA8121 Analyzer (Menarini, Florence, Italy).

\section{Lipoprotein metabolism studies}

Chylomicrons were detected after isolation from plasma by preparative ultracentrifugation under standard conditions. apo $C_{\text {II }}$ was determined by isoelectric focusing of very low density lipoproteins (VLDL) in polyacrylamide gels as previously described (6). An oral fat load test was performed during the fourth week (day 22) using a protocol already reported using retinyl palmitate as a marker of the metabolism of chylomicrons and 'remnants' (9, 10). LPL and hepatic lipase (HL) were determined according to the method described by Krauss et al. (11). Samples were collected after an overnight fasting before and after $10 \mathrm{~min}$ after rapid i.v. administration of sodium heparin (10 units of heparin $/ \mathrm{kg}$ ). Plasma was immediately separated by a refrigerated centrifuge and stored at $-80^{\circ} \mathrm{C}$ until determination. In this method a normal serum is added to the emulsion as an external source of apoC $C_{I I}$. In an additional set of experiments, the sample of the proband was used in the assay of normal plasma to evaluate its own influence on lipolytic enzymes. These experiments were performed by MR at the Lawrence Berkeley National Laboratory, Berkeley, CA, USA, courtesy of Dr R. M. Krauss. The apoE genotypes were determined using the PCR method described by Hixson and Vernier (12). For the analysis of LPL gene single nucleotide polymorphisms (SNPs), genomic DNA was isolated from whole blood by standard methods. PCR was performed using the PvuII and HindIII enzymes (13).

\section{Glucose metabolism studies}

Venous blood samples for anti-islet autoantibodies were collected and refrigerated at $-70{ }^{\circ} \mathrm{C}$ until assayed in two independent laboratories (CG, Palermo, Italy and

Table 3 Metabolic and immunologic parameters in a 9-year-old girl with a massive triglyceride elevation and fasting chylomicronemia at admittance to hospital (day 1) and during the first 5 months. Antibodies were measured in two independent laboratories using specific radioimmunoassays.

\begin{tabular}{|c|c|c|c|c|c|c|c|c|}
\hline Time & $\begin{array}{c}\text { DMG } \\
(\mathrm{mmol} / \mathrm{l})\end{array}$ & $\begin{array}{c}\text { UK } \\
(\mathrm{mmol} / \mathrm{l})\end{array}$ & $\begin{array}{c}\mathbf{H b A}_{1 \mathrm{c}} \\
(\%)\end{array}$ & $\begin{array}{c}\text { IR } \\
(\mathrm{U} / \mathrm{kg} B W)\end{array}$ & $\begin{array}{l}\text { ICA (JDF IU) } \\
(<2.5)^{\star}\end{array}$ & $\begin{array}{c}\text { GAD65 (IU/ml) } \\
(<24.6)^{*}\end{array}$ & $\begin{array}{l}\text { IA-2 (IU/ml) } \\
(<2.74)^{*}\end{array}$ & $\begin{array}{c}\text { IAA }(\mathrm{nU} / \mathrm{ml}) \\
(<39) *\end{array}$ \\
\hline Day 1 & 12.1 & + & & 1.65 & NA & NA & NA & NA \\
\hline Day 2 & 8.1 & + & & 1.72 & NA & NA & NA & NA \\
\hline Day 3 & 5.8 & - & & 1.75 & NA & NA & NA & NA \\
\hline Day 5 & 6.5 & - & & 1.60 & NA & NA & NA & NA \\
\hline Day 6 & 7.2 & - & & 1.03 & NA & NA & NA & NA \\
\hline Day 8 & 9.5 & - & 6.9 & 1.05 & Neg. & Neg. & Neg. & 12 \\
\hline \multicolumn{9}{|c|}{ Day 9: enteral feeding } \\
\hline Week 2 & 6.2 & - & & 0.32 & NA & NA & NA & NA \\
\hline Week 3 & & - & & 0.35 & Neg. & $\mathrm{Neg}$ & Neg. & NA \\
\hline Week 4 & 7.4 & - & 6.9 & 0.50 & NA & NA & NA & NA \\
\hline Month 3 & 9.8 & - & 7.8 & 0.62 & Neg. & Neg. & Neg. & NA \\
\hline Month 5 & 11.3 & - & 9.6 & 0.82 & Neg. & Neg. & Neg. & NA \\
\hline Month 6 & 6.1 & - & 7.2 & 1.08 & Neg. & Neg. & Neg. & NA \\
\hline
\end{tabular}

DMG, daily mean glycemia; UK, urinary ketones; $\mathrm{HbA}_{1 \mathrm{c}}$, glycated hemoglobin; IR, insulin requirement; BW, body weight; ICA, islet cells antibodies; GAD65, anti-glutamic acid decarboxylase antibodies; IA-2, anti-islet antigen 2 antibodies; IAA, insulin autoantibodies; Neg., absence of antibodies; NA, not analyzed.

* Normal values. 
AP, Miami, FL, USA). Cytoplasmatic islet cells antibodies (ICA) were measured on frozen sections of human pancreas by indirect immunofluorescence. This ICA assay had a sensitivity of $100 \%$, with a specificity of $74.4 \%$ in new onset patients younger than 30 years. The values are considered positive $>2.5$ Juvenile Diabetes Foundation IU. Antibodies to glutamic acid decarboxylase (GAD65) and the tyrosine phosphatase-like antigen IA-2 were measured in triplicate using specific radioimmunoassays. For GAD65 antibodies the GAD65 clone was used, kindly provided by A Lernmark $(14,15)$; for IA-2 antibodies two IA-2 clones were used together to maximize sensitivity, kindly provided by G S Eisenbarth $(14,16,17)$ and E Bonifacio (18-20). The upper limit of normal for GAD65 antibody levels is an index of 24.6. The upper limit of normal for IA-2 antibody levels is 2.74. In the 2002 Diabetes Autoantibody Standardization Program the sensitivity and specificity for the GAD65 and IA-2 antibody tests combined were 92\% and 88\% (GAD65: 80\% sensitivity, 93\% specificity; IA-2: $68 \%$ sensitivity, $85 \%$ specificity). Insulin autoantibodies were determined with a fluid phase radioassay using polyethylene glycol precipitation with a method with assayed specificity of $100 \%$ and sensitivity of $85 \%$. Normal values were $<39 \mathrm{nU} / \mathrm{ml}$. C-peptide levels were measured after i.v. glucagon ( $1 \mathrm{mg}$, bolus) at the following times $-15,0,1,3$ and $6 \mathrm{~min}$ every 3 months for the entire period of follow-up. The hyperinsulinemic-euglycemic glucose clamp was performed under standard conditions and the rate of glucose metabolism $(M)$ was calculated by dividing the glucose infused during the last $40 \mathrm{~min}$ of the clamp by the body weight in kilograms (mg/kg per min) (21).

\section{Results}

The lipoprotein parameters of the proband (at admittance) and her relatives are shown in Table 1 . The proband's plasma triglyceride levels were extremely high whereas her parents and brothers had normal lipid levels. apoE genotypes were not informative and SNPs for LPL revealed no linkage with the LPL gene. A normal apo $C_{\text {II }}$ was demonstrated in the proband.

Table 2 shows the plasma lipids of the proband at admittance and during the following 6 months. Plasma lipid levels fell rapidly following the institution of parenteral nutrition. After a few weeks, triglyceride levels normalized and remained normal afterwards. Insulin therapy was started with a significant improvement of glucose metabolism and a rapid disappearance of urinary ketones (Table 3). Glucose control was obtained by insulin therapy; insulin requirement was low after the discharge and then was stable around $1 \mathrm{U} / \mathrm{kg}$ body weight with a fair metabolic control. Humoral markers associated with type 1 diabetes were consistently negative at onset and during the first 6 months after diabetes onset. C-peptide measurements, both fasting and stimulated, including a glucagon test (at week 2 and during the entire follow-up, every 3 months) were consistent with lack of insulin secretion $(<0.045 \mu \mathrm{g} / \mathrm{l})$ for the entire period of follow-up (2 years). A hyperinsulinemic-euglycemic clamp (week $6, M=4.3 \mathrm{mg} / \mathrm{kg}$ per min) demonstrated that she was insulin deficient and had no insulin resistance, with C-peptide levels (at 0, 30, 60, 90 and $120 \mathrm{~min}$ ) under the detection limit for the entire test.

LPL and HL were in the normal range (respectively $14.9 \pm 1.1 \mu \mathrm{mol}$ free fatty acids (FFA)/ml per $\mathrm{h}$ and

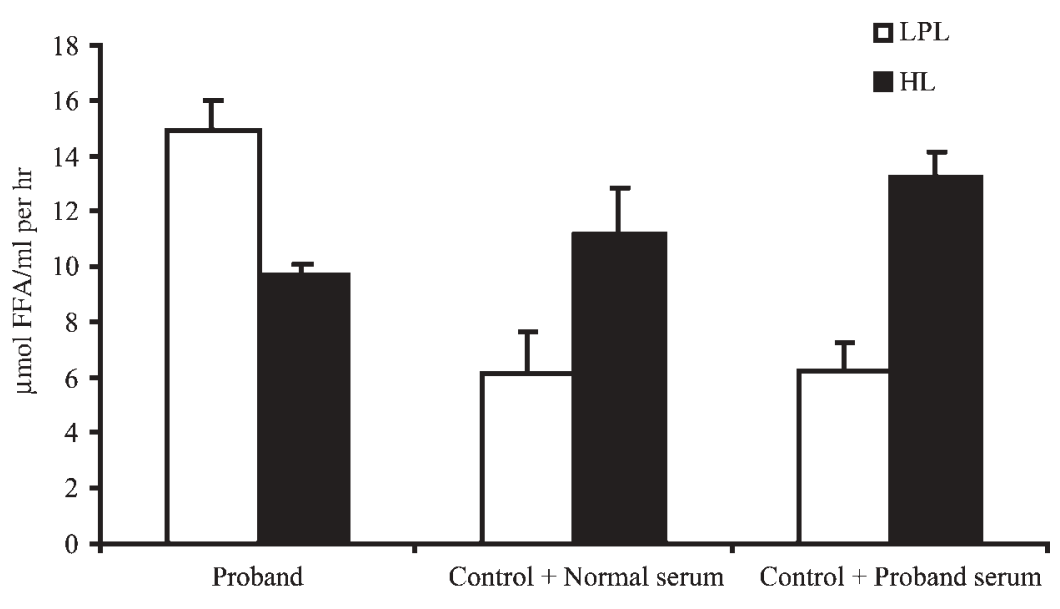

(a)

(b)

(c)

Figure 2 LPL and HL in the proband (a), in controls plus a normal serum (b) and in controls plus proband serum (c). Data shown in (a) and (c) are the mean of three different determinations; control sera in (b) and (c) represent pooled sera from normal subjects selected at the Lawrence Berkeley National Laboratory, Berkeley, CA, USA. Vertical bars represent S.D. 


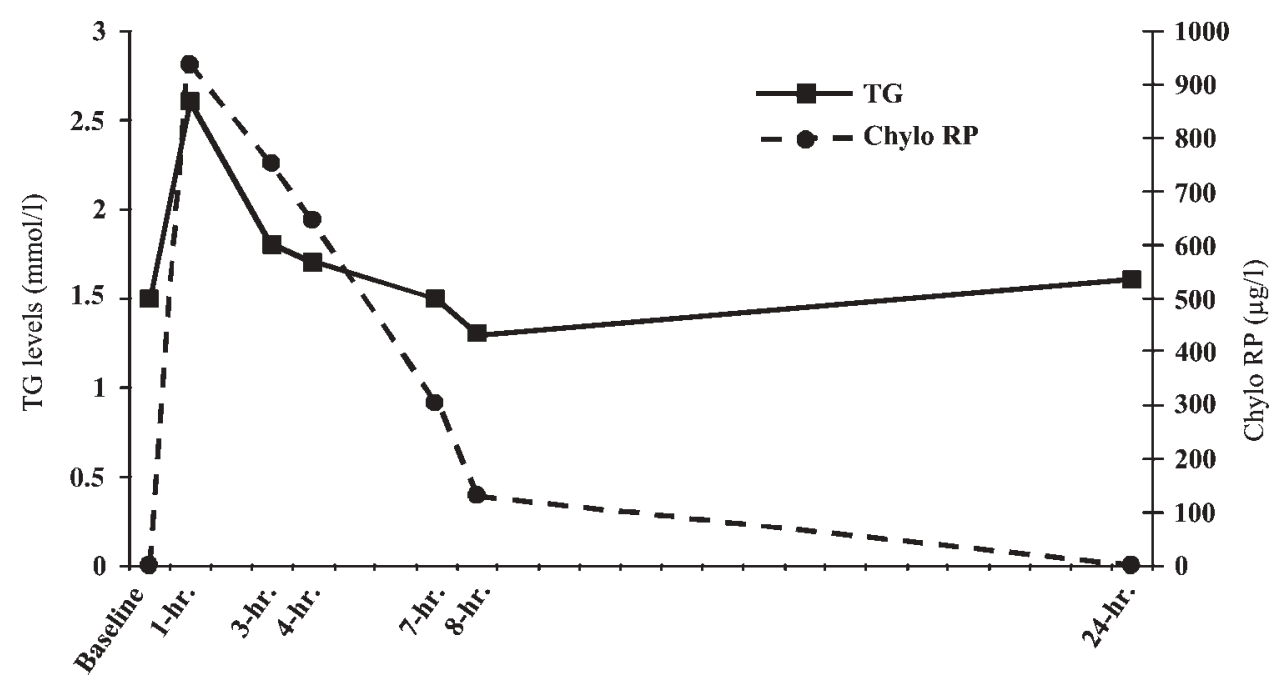

Figure 3 Triglyceride (TG) levels and retinyl palmitate in chylomicrons (Chylo RP) after oral fat load in the proband.

9.7 $\pm 0.4 \mu \mathrm{mol}$ FFA/ml per h, Fig. 2). The serum of the proband normally activated control plasma and LPL and HL activities were similar to those detected when a normal sample was added.

After an oral fat load the proband had a triglyceride peak at the first hour and then rapidly cleared triglyceride levels. A similar behavior was observed for chylomicrons' retinyl palmitate as a marker of the metabolism of these lipoprotein particles (Fig. 3). This experiment was even conducted in conditions of insulin deficiency. Since the results were completely normal, we avoided repeating the test while on insulin therapy.

\section{Discussion}

Type 1 diabetes is an autoimmune disease. About 80$90 \%$ of patients have autoantibodies against islet cell molecules in their serum at the time of clinical onset. The HLA locus accounts for approximately 50\% of the familial aggregation and both susceptible and protective HLA haplotypes have been defined (22). Three islet antigens, insulin, GAD65 and IA-2 are the most common targets of autoimmune responses $(1,22)$. The synergistic action of $\mathrm{CD}^{+}$and $\mathrm{CD}^{+} \mathrm{T}$ cells is thought to mediate $\beta$-cell destruction $(23,24)$. Environmental factors have also been associated with type 1 diabetes. To date, environmental risk determinants can be classified into three groups: viral infections (e.g. Coxsackie virus and cytomegalovirus), early infant diet (e.g. breast feeding vs early introduction of cow's milk components) and toxins (e.g. nitroso derivatives) (3). No data exist showing that the chylomicronemic syndrome may cause $\beta$-cell destruction.

Chylomicrons are large, buoyant, triglyceride-rich lipoproteins of intestinal origin (25). In the fasting state, chylomicrons are absent in human plasma: their presence, together with a massive hypertriglyceridemia, is the feature of the chylomicronemic syndrome (4). This rare syndrome may be the consequence of genetic disorders as well as of secondary conditions, including diabetes (7). There is also some evidence for transient forms of this lipoprotein abnormality $(8,26)$.

At admission we hypothesized that the severe hypertriglyceridemia was the consequence of the onset of the diabetes (7). However, mild hyperglycemia such as the one observed is unlikely to be the explanation for such severe chylomicronemia. We therefore investigated the presence of an associated defect in the lipoprotein metabolism. Personal and familial history did not show evidence of lipid disorders (including a low HDL phenotype), no linkage with LPL gene was found and apoE genotypes were found to be $\epsilon 3 / \epsilon 3$. Furthermore, we were not able to find any apo $C_{\text {II }}$ abnormalities and lipolytic enzymes (assayed after normalization of plasma triglyceride since pancreatitis discouraged us from using infusion of heparin for these tests) were in the normal range. The proband's chylomicronemic sample activated LPL in a normal plasma: these experiments demonstrate that there is no inhibitor of LPL in the serum of the proband and that apoC $\mathrm{C}_{\mathrm{II}}$ of the proband is able to activate a normal LPL (25). After a few months the patient rapidly cleared an oral fat load test in conditions of insulin deficiency, with a triglyceride peak of $2.6 \mathrm{mmol} / \mathrm{l}$ after $1 \mathrm{~h}$. In addition, data regarding retinyl palmitate metabolism confirmed no delay in the clearance of chylomicron particles. Therefore, the only plausible explanation for the high lipid levels observed transiently at the time of onset remains a transient LPL deficiency, a rare condition indistinguishable from genetic forms of LPL deficiency $(8,26)$, occasionally associated with a high-fat diet, which was a documented factor in this patient.

The patient did not have any of the HLA and autoantibody markers typical of type 1 diabetes. She carried the DR1 and DR6 HLA antigens and several serum samples 
were consistently negative for type 1 diabetes-associated autoantibodies (Table 3) (1, 24). A glucose clamp failed to demonstrate insulin resistance and there was no family history of type 2 diabetes or maturity onset diabetes in youth (data not shown). Repetitive assays of both fasting and stimulated C-peptide levels, also obtained after i.v. glucagon stimulus, showed deficient $\beta$-cell function soon after the first 2 weeks when a normalization of blood glycemic levels was achieved by daily insulin therapy (Table 3). The causes of the observed $\beta$-cell secretory defect remain unknown, and a viral infection cannot be excluded (27). However, since lipid toxicity has been demonstrated in $\beta$-cells in vitro, the sudden and massive elevation of chylomicrons may have contributed to diabetes development (28). Although diabetes is rarely a consequence of pancreatitis, the possible toxicity of high lipid levels and perhaps a viral infection may have heightened the pronounced sensitivity of $\beta$-cells to inflammation and may help to explain the onset of diabetes in this child. In conclusion, we have identified a rare young patient in whom a severe and transient hyperlipidemia may contribute to explain the onset of diabetes in the absence of typical markers of autoimmune diabetes.

\section{Acknowledgements}

The authors wish to thank Dr Ronald M. Krauss from the Lawrence National Berkeley Laboratory, Berkeley, CA for help in the determination of lipolytic enzymes.

\section{References}

1 Atkinson MA \& Eisenbarth GS. Type 1 diabetes: new perspectives on disease pathogenesis and treatment. Lancet 2001358 221-229.

2 Winter WE, Harris N \& Schatz D. Type 1 diabetes islet autoantibody markers. Diabetes Technology \& Therapeutics $20024817-839$.

3 Kawasaki E \& Eisenbarth GS. High-throughput radioassays for autoantibodies to recombinant autoantigens. Frontiers in Bioscience 20005 E181-E190.

4 Santamarina-Fojo S. The familial chylomicronemia syndrome. Endocrinology and Metabolism Clinics of North America 199827 $551-567$.

5 Nauck MS, Nissen H, Hoffmann MM, Herwig J, Pullinger CR, Averna $\mathrm{M}$ et al. Detection of mutations in the apolipoprotein CII gene by denaturing gradient gel electrophoresis. Identification of the splice site variant apolipoprotein CII-Hamburg in a patient with severe hypertriglyceridemia. Clinical Chemistry $1998 \mathbf{4}$ 388-396.

6 Zanelli T, Catapano AL, Averna MR, Barbagallo CM, Liotta A, Giardina CF et al. A new case of apo C-II deficiency with a nonsense mutation in the apo C-II gene. Clinica Chimica Acta 1994 $224111-118$.

7 Chait A \& Brunzell JD. Acquired hyperlipidemia (secondary dyslipoproteinemias). Endocrinology and Metabolism Clinics of North America $199019259-278$.

8 Goldberg IJ, Paterniti JR Jr, Franklin BH, Ginsberg HN, GinsbergFellner F \& Brown WV. Transient lipoprotein lipase deficiency with hyperchylomicronemia. American Journal of Medical Science $198328628-31$.

9 Barbagallo CM, Averna MR, Amato S, Davì G, Pagano M, Noto D et al. Lipid and apoprotein behaviour after oral fat load in hypertriglyceridemia. Diabète et Métabolisme 199117 512-519.
10 Cortner JA, Coates PM, Le NA, Cryer DR, Ragni MC, Faulkner A et al. Kinetics of chylomicron remnant clearance in normal and in hyperlipoproteinemic subjects. Journal of Lipid Research 1987 28 195-206.

11 Krauss RM, Levy RI \& Fredrickson DS. Selective measurement of two lipase activities in postheparin plasma from normal subjects and patients with hyperlipoproteinemia. Journal of Clinical Investigation $1974 \mathbf{5 4} 1107-1124$.

12 Hixson JE \& Vernier DT. Restriction isotyping of human apolipoprotein E by gene amplification and cleavage with HhaI. Journal of Lipid Research 199031 545-548.

13 Gotoda T, Yamada N, Murase T, Shimano H, Shimada M, Harada K et al. Detection of three separate DNA polymorphisms in the human lipoprotein lipase gene by gene amplification and restriction endonuclease digestion. Journal of Lipid Research 199233 1067-1072.

14 Verge CF, Gianani R, Kawasaki E, Yu L, Pietropaolo M, Jackson RA et al. Prediction of type I diabetes in first-degree relatives using a combination of insulin, GAD, and ICA $512 \mathrm{bdc} / \mathrm{IA}-2$ autoantibodies. Diabetes $199645926-933$.

15 Vandewalle CL, Falorni A, Svanholm S, Lernmark A, Pipeleers DG \& Gorus FK. High diagnostic sensitivity of glutamate decarboxylase autoantibodies in insulin-dependent diabetes mellitus with clinical onset between age 20 and 40 years. The Belgian Diabetes Registry. Journal of Clinical Endocrinology and Metabolism $199580846-851$.

16 Rabin DU, Pleasic SM, Palmer-Crocker R \& Shapiro JA. Cloning and expression of IDDM-specific human autoantigens. Diabetes 199241 183-186.

17 Gianani R, Rabin DU, Verge CF, Yu L, Babu SR, Pietropaolo M et al. ICA512 autoantibody radioassay. Diabetes $1995 \mathbf{4 4} 1340-1344$.

18 Naserke HE, Ziegler AG, Lampasona V \& Bonifacio E. Early development and spreading of autoantibodies to epitopes of IA-2 and their association with progression to type 1 diabetes. Journal of Immunology $1998 \mathbf{1 6 1} 6963-6969$.

19 Lampasona V, Bearzatto M, Genovese S, Bosi E, Ferrari M \& Bonifacio E. Autoantibodies in insulin-dependent diabetes recognize distinct cytoplasmic domains of the protein tyrosine phosphatase-like IA-2 autoantigen. Journal of Immunology 1996 $1572707-2711$.

20 Park YS, Kawasaki E, Kelemme K, Yu L, Schiller MR, Rewers M et al. Humoral autoreactivity to an alternative spliced variant of ICA512/IA-2 in type 1 diabetes. Diabetologia $2000 \quad \mathbf{4 3}$ 1293-1301.

21 De Fronzo RA, Tobin JD \& Andres R. The glucose clamp technique. A method for the quantification of beta cell sensitivity to glucose and of tissue sensitivity to insulin. American Journal of Physiology $1979237214-223$.

22 Wucherpfennig KW \& Eisenbarth GS. Type 1 diabetes. Nature Immunology 20012 767-768.

23 Stassi G, De Maria R, Trucco G, Rudert WA, Testi R, Galluzzo A et al. Nitric oxide primes pancreatic $\beta$-cells for Fas-mediated destruction in IDDM. Journal of Experimental Medicine 1997186 1193-1200.

24 Giordano C \& Galluzzo A. Fas-mediated apoptosis in human type I diabetes: its possible role in the destruction of pancreatic $\beta$-cells. Diabetes, Nutrition and Metabolism 199710 233-241.

25 Ginsberg HN. Lipoprotein physiology. Endocrinology and Metabolism Clinics of North America 199827 503-519.

26 Nagasaka H, Kikuta H, Chiba H, Murano T, Harashima H, Ohtake A et al. Two cases with transient lipoprotein lipase (LPL) activity impairment: evidence for the possible involvement of an LPL inhibitor. European Journal of Pediatrics 2003162 132-138.

27 Lernmark A. Rapid-onset type 1 diabetes with pancreatic exocrine dysfunction. New England Journal of Medicine $2000342344-345$.

28 Shimabukuro M, Wang MY, Zhou YT, Newgard CB \& Unger RH. Protection against lipoapoptosis of beta cells through leptindependent maintenance of Bcl-2 expression. PNAS 199895 9558-9561.

Received 23 May 2003

Accepted 12 February 2004 